\title{
Lung function test: present and future perspective in Bangladesh
}

\author{
DK Sunyal
}

\begin{abstract}
Lung function tests are the most important determinants to assess the status of the respiratory function. Pulmonary function tests give an idea about the status of pulmonary dysfunction but no system has been developed in Bangladesh to routinely assess the respiratory function. During the last three decades lung function tests have evolved from physiological and clinical studies and these are widely used in assessing respiratory status. In addition to their use in clinical case management, they have become a part of routine health examinations in respiratory, occupational and sports medicine, public health screening, school health program and industrial health. In Bangladesh only a few works have been done but in neighboring countries, a great number of works have been performed on this aspect. For carrying out this type of research work sophisticated instruments, laboratory facilities, research grant, etc are necessary. It is necessary to expand the knowledge of lung function tests in widely different conditions.
\end{abstract}

Key words: Lung function test, present and future perspective, Bangladesh.

\section{Introduction}

Lung function tests are the most important determinants to assess the status of the respiratory function. In Bangladesh air pollution is one of the common hazards for any kind of respiratory dysfunction which may be related to inhalation of the polluted air causing damage to the membrane structure and mechanical efficiency leading to alteration in the functional properties of the lungs, as a result various respiratory disorder occurs. Duration of exposure, ageing and smoking can also complicate pulmonary functions. ${ }^{1}$

In developed countries, pulmonary function tests are part of all routine clinical assessment of respiratory function. As the number of centers, equipment and measuring method grew, the need to standardize equipment, calibration and measurement techniques became necessary \& guidelines were formulated by the European Respiratory Society \& the American Thoracic Society. ${ }^{2}$
During the last three decades lung function tests have evolved from physiological and clinical studies and these are widely used in assessing respiratory status. In addition to their use in clinical case management, they have become a part of routine health examinations in respiratory, occupational, sports medicine and in public health screening. ${ }^{3}$

\section{Bangladesh perspective: present and future \\ In Bangladesh a few works have been done. These are some aspects of lung function measurement in healthy subjects of different age groups, lung function tests in adults in industrial setings, study of respiratory func- tion, study of effects of smoking on pulmo- nary function, study on the peak expiratory flow rate in normal subjects, study on effects of air pollution on some aspects of pulmo- nary function in urban industrial and non industrial adolescents, effects of vitamin A, C \& $E$ on some aspects of lung function in}


smokers, comparative study on effects of open and laparoscopic upper abdominal surgery on some aspects of pulmonary function, some aspects of lung function tests in patients with bronchial asthma both before and after taking bronchodilator inhaler, effects of physical exercise on pulmonary function in adolescent athletes, lung function in teenage Bangladeshi boys and girls, etc. ${ }^{4}$ Lung function parameters of Bangladeshi male subjects in different living conditions. ${ }^{5}$

Pulmonary function tests give a clear idea about the status of pulmonary dysfunction. But no system has been developed in Bangladesh for routine assessment of the respiratory function. In neighboring countries of Bangladesh a great number of works have been performed on this aspect. For carrying out this type of research work sophisticated instrument, laboratory facilities, research grant, etc are necessary. Routine lung function tests may be involved in health examination and school health program. It is necessary to expand the knowledge of lung function tests in widely different conditioned e.g population, industry, etc by research workers and to develop facilities for routine examination of lung function tests for different segments of population.

The largest change in spirometric pulmonary function testing is the introduction of the digital computer for data acquisition and reduction. Computerassisted spirometry can enhance the effectiveness of spirometric testing by increasing test accuracy, increasing patient acceptance, and decreasing the time necessary to complete the test and its interpretation. Any computer-assisted spirometer is easy to use and displays clearly and properly reports test results. ${ }^{6}$

\section{Role of Physiologist}

Physiologist can assist the clinical workers by performing lung function tests from the physiological aspects. Instruments and appliances are available in the physiology laboratory like micro spirometer, peak flow meter, blood gas analyzer, etc can be used for such assessment of lung function. Physiolo- gists usually perform their measurement and test based on measurement of lung volumes and capacities by spirometer, also by doing lung compliance, airway resistance, measurement dead space air and maximum breathing capacity and others.

Although these test are not based upon ultrasonography or radiological procedures, all these physiological tests may help clinicians greatly for diagnosis and follow up of the patient suffering from chronic lung diseases.

\section{References}

1. Geetha B, Nair RH, Kesavachandran C, Chandy S, Shashidhar S. Pulmonary function in workers of fertilizer and chemical industry. Indian $\mathrm{J}$ Physiol Pharmacol 2001;45(2): 215-21.

2. Gutierrez C, Ghezzo RH, Abboud RT, et al. Reference values of pulmonary function tests for Canadian Caucasians. Can Respir J 2004; 11(6):414-24.

3. American Thoracic Society (Medical section of the American Lung Association). Lung function testing selection of reference values and interpretative strategies. Am Rev Respir Dis 1991;144:1202-18.

4. Rahman MA, Ullah MB, Begum A. Lung function in teenage Bangladeshi boys and girls. Respir Med 1990;84(1):47-55.

5. Choudhury S, Alam MS, Begum QN. Lung function parameters of Bangladeshi male subjects in different living conditions. Bangladesh Med Res Counc Bull 1997;23(1):30-3.

6. Larson JK. Computer-assisted spirometry. Respir Care 1982;27(7):839-41.

7. Begum MA, Uddin KMF. Some aspects of lung function measurements in healthy subjects of different age groups. Bangladesh J Physiol Pharmacol 1995;11(1).

8. Akther N, Begum N. Some aspects of pulmonary function in urban industrial adolescent female. Bangladesh $J$ Physiol Pharmacol 2004; 20(12):28-30. 
9. Siddiqul NA, Begum N, Islam N, et al. Effect of physical training on peak expiratory flow rate (PEFR) in adolescents. Bangladesh $J$ Physiol Pharmacol 2001;17(1):18-20.

10. Rahman N, Begum N, Hai MA. A comparative study on effects of abdominal surgery on some aspects of lung func- tion. Bangladesh $\mathrm{J}$ Physiol Pharmacol 2001;17(2):50-2.

11. Sultana R, Begum N, Begum $S$, et al. FVC, FEV1 \& FEV1/FVC\% in female bronchial asthma patients both before \& after taking bronchodilator inhaler. Bangladesh $J$ Physiol Pharmacol 2002;18(1/2):35-8.

Suggestion for citation of the above:

Sunyal DK. Lung function test: present and future perspective in Bangladesh. Mediscope 2016;3(2):36-8. 